\title{
Critical Factors in Managing Relationally Demanding Jobs, in Care for Very Ill and/or Dying Patients: A Phenomenological Study among Public Hospital Nurses
}

\author{
Asgerdur Bjarnadottir ${ }^{1 *}$, Monica Lillefjell ${ }^{2}$ \\ ${ }^{1}$ Faculty of Health Education and Social Work, Sør-Trøndelag University College, Trondheim, Norway \\ ${ }^{2}$ Center for Health Promotion Research HIST/NTNU and Department of Occupational Therapy, Faculty of \\ Health Education and Social Work, Sør-Trøndelag University College, Trondheim, Norway \\ Email: *Asgerdur.Bjarnadottir@hist.no
}

Received 29 December 2014; accepted 15 January 2015; published 19 January 2015

Copyright (C) 2015 by authors and Scientific Research Publishing Inc.

This work is licensed under the Creative Commons Attribution International License (CC BY).

http://creativecommons.org/licenses/by/4.0/

(c) (i) Open Access

\begin{abstract}
Background: Workload, interpersonal relationships, professional conflict and the emotional cost of providing care are potential sources of stress and burnout among nurses. Based on experiences of hospital nurses, this paper aims to identify critical factors for nurses in managing relationally demanding situations in care for very ill and/or dying patients. Methods: In-depth interviews were carried out with six nurses, working in a medium-sized hospital in Norway. The interviews were analysed using an interpretative phenomenological analysis. Results: The lack of identification with the core aspect of the job, relational contact with patients and relatives, and external motivation were found as potential barriers for managing relationally demanding jobs. The results also indicate that the nurses' experiences of symptoms of burnout can be a result of demands that exceeded the nurses' resources. A match between personal capacity and demands, mutual support among colleagues and leadership support, and contextual factors are critical to prevent the negative process of burnout. Conclusion: The results underscore the importance of an early response to employees who are beginning to struggle at work and the relevance of a true match between personal capacity and job demands. Moreover support among colleagues and leadership seems critical to prevent a negative process of burnout and help to manage relationally demanding jobs.
\end{abstract}

\section{Keywords}

Relationally Demanding Jobs, Symptoms of Burnout, Personal Capacity, Motivation, Interpretative

"Corresponding author.

How to cite this paper: Bjarnadottir, A. and Lillefjell, M. (2015) Critical Factors in Managing Relationally Demanding Jobs, in Care for Very III and/or Dying Patients: A Phenomenological Study among Public Hospital Nurses. Open Journal of Nursing, 5, 58-67. http://dx.doi.org/10.4236/ojn.2015.51007 


\section{Phenomenological Analysis}

\section{Introduction}

Several studies on the work conditions of nurses have focused on health and well-being. Generally, these studies indicate that nursing is rather stressful [1] [2]. The organisational environment of these jobs is often characterised by high demands and lack of resources [3]. Although professional demands are not necessarily negative, the sustained physical and/or psychological effort or skills required are associated with considerable costs [4].

Failure in meeting these professional demands or standards may potentially contribute to negative feelings and self-criticism, and lead to symptoms of burnout in terms of emotional fatigue and problems in maintaining health over time [1] [5]-[8].

Workload, interpersonal relationships, professional conflict and the emotional cost of providing care are pointed out as potential sources of stress and burnout among nurses [1].

Burnout is defined as "a syndrome of emotional exhaustion, depersonalisation, and reduced personal accomplishment that can occur among individuals who work with people in some capacity" [9], and is distinguished from occupational stress with respect to time. Burnout can be considered a response to prolonged job stress, where the demands at the work place exceed an individual's resources [3]. It is said that everybody can experience stress, but that burnout can only be experienced by those who entered their jobs enthusiastically with high goals and expectations. Burnout is characterised by exhaustion and cynicism [9], and related to a variety of negative outcomes, like job dissatisfaction, lower performance than colleagues, lower commitment levels [3], as well as a high number of a health problems [10].

Generally, an intensive work effort increases the risk of adverse health, unhappiness and burnout [3] [11] [12].

The strong and internalised ethic of responsibility among professionals might result in adoption of external standards without fully identifying with them, which in turn can lead to health problems [13]. In nursing, the general norm is to be selfless and to put the needs of others in the first place, doing whatever it takes to help the patients. The therapeutic relationships that nurses develop with patients entail an ongoing and intense level of personal emotional contact that may potentially cause an erosion of a positive psychological state [1]. Previous studies suggest that the emotional labour characterising the everyday practice of human service professionals, including nurses, may be a prominent factor when predicting burnout among nurses and have a higher effect than more common job stressors [14] [15]. It is suggested that nurses experiencing burnout are deviant in the sense that they act without intent or refrain from acting while distancing themselves from their work in order to prevent further reduction of mental resources [14] [15].

Nurses with a direct experience of life and death issues are at risk of work stress because of their exposure to frequent deaths and family grieving. However, there is no strong evidence that palliative care or hospital nurses experiences higher levels of stress than nurses in other disciplines [16]. A study of determinants of burnout among public hospital nurses revealed that sociodemographic factors play a small, but significant role in predicting burnout [17]. Spooner-Lane \& Patton [17] found that role overload, job conflicts and role boundary contributed to higher levels of emotional exhaustion, while role boundary and professional uncertainty were related to higher levels of depersonalisation. Only supervisor's support had a significant main effect on depersonalisation and personal accomplishment. However, no evidence was found to indicate that work support had a buffering effect on the stress-burnout relationship. In contrast, a study by Laschinger, Wong \& Grau [18] pointed to authentic behaviour of nursing leaders as important to nurses' perceptions of structurally empowering conditions in their work environments, regardless of experience level, as a contribution to lower levels of emotional exhaustion and cynicism. This is further supported by Peters, Cant, Sellick et al. [16], who suggested that managers have a key role in providing education and training for palliative care nurses to support their personal development and to help reduce the vulnerability and the impact of stress in the workplace. Moreover, a recent study [19] showed that motivation is an important factor that enables employees to leave the negative cycle of burnout.

Based on experiences of hospital nurses, the aim of this study is to identify critical factors for nurses in managing relationally demanding situations in care for very ill and/or dying patients. 


\section{Methods}

Utilising phenomenological research, critical factors for nurses in managing relationally demanding situations in care for very ill and/or dying patient is identified, based on the experiences of six hospital nurses [20].

Data were collected through in-depth interviews [21], and an interpretative phenomenological analysis (IPA) [22] was used in the interpretation of the data.

Interpretative Phenomenological Analysis (IPA) has specifically been developed by Jonathan Smith to allow rigorous exploration of ideographic subjective experience and, more specifically, social cognitions [22]. IPA's theoretical foundation is strongly influenced by phenomenology, which originated with Husserl's attempts to construct a philosophical science of consciousness, with hermeneutics (the theory of interpretation), and with symbolic-interactionism, which suggests that the meaning of an individual ascribes to events are of central concern but are only accessible through an interpretative process [22]. The approach used in IPA is phenomenological in the sense that it involved a detailed examination of the participant's life-world and personal experiences. IPA studies are conducted on small sample sizes, and the aim of the study is to say something in detail about the understanding of this particular group rather than make more general claims [20]. A sample of six is therefore considered an acceptable size for this kind of study.

The purpose of using IPA as an analytical method in this study, was to create a greater understanding of the experiences of hospital nurses in managing critical relationally-demanding situations in care. In the process of the analysis, IPA recognises the researcher's interpretation of the material [23].

\subsection{Sample}

This study is based on interviews with six nurses who work with patients, representing all age groups, from young children to adults, who were seriously ill and/or dying. The nurses were the primary contact nurses for a certain number of patients and their immediate families. The nurses were aged between 26 and 53, and their work experience in their present department varied from 3 to 11 years. Five of the participants worked full time, while one had $75 \%$ employment. The participants were either married or co-habiting, and had children and/or teenagers staying at home.

The data were collected in a medium-sized hospital in Norway, and before the interviews were conducted, a strategic selection of hospital departments was made [24] [25]. Inclusion criteria were departments who treated patients with a direct experience of life-and-death issues and where the jobs for the nurses were relationally demanding. An information leaflet and criteria for inclusion were subsequently sent to the departments, and respondents who had worked at the same department for at least three years were encouraged to voluntary enlist as participants. All nurses at the three departments, who fulfilled the inclusion criteria, were invited to participate. The sample consists of both women and men.

\subsection{Collection of Data}

The interviews were conducted by the first author, and the data were collected through semi-structured in-depth one-to-one interviews with open-ended questions. Semi-structured interviews are probably the best way to collect data for an IPA study. This form of interviewing allows the researcher and participants to engage in a dialogue, and the investigator is able to probe interesting and important areas which arise [20]. The following topics were covered in the interviews: work engagement, motivation for applying for admission to the nursing study programme, life values, work resources, work requirements, health and the ability to care for one's self. In this paper the focus is on critical factors for nurses in managing the job. All interviews were done at the workplace of the participants, and each interview lasted for 1.5 - 2 hours.

The interviews were tape recorded and transcribed verbatim. At the completion of each interview, the first author listened to selected parts of the recording that could possibly cause changes to the interview guide. The interview guide was subsequently subjected to continuous adjustment and improvement. An example of this is when the six nurses' problems in practice were discovered, and in-depth questions about their daily functioning on the job were immediately formulated.

\subsection{Data Analysis}

The analysis was carried out according to Interpretative phenomenological analysis (IPA) with the aim of clari- 
fying situations lived through by persons in everyday life, and the context in which they appears [20]. This generates description of the phenomena of the nurses' job experience and insightful understanding.

The analysis was carried out in several steps-see examples of the analysis in the first theme, given in Table 1.

Initially, the first author read one interview through several times in order to capture the initial understanding, before moving on to others. Notes were written on the basis of initial themes, associations or questions, and the notes resulting from the interviews were also studied. In step two, the connection between the emerging themes in the meaning unit was examined, and some of the themes were clustered together. Keywords, like problems with interpersonal relations, which captured the essence of the informant's statements, were used to identify concurrent themes. Data saturation resulted when no new themes emerged from the analytic approach. The third step involved providing structure to the analysis. The aim with this step was to structure the emerging theme from the data and increase the understanding of the processes. The fourth step was dedicated to further refining the themes by creating a summary that helped divide them into main themes and sub-themes. Theory was applied under steps three and four in order to increase the understanding of the research material. The findings are evident in three main-themes and seven sub-themes-see Table 2.

IPA analysis allows for viewing research as a dynamic process where the analysis represents an ongoing process of interpretation by the researcher. The method used, is connected to hermeneutics and theories of interpretation with a two-stage interpretation process, or a double hermeneutic process [23]. Direct quotes from the interviews are presented in the text as quotations.

\subsection{Validity}

In order to obtain as much insight as possible [20], the authors engaged in reflective discussions concerning the interpretation of the data. Based on reflective discussions, the authors agreed on themes and sub-themes. The first author also had a discussion about the study, its method and findings, with colleagues from other professions in lectures and seminars.

Table 1. Example of structural analysis in the first theme; "The struggle to handle the core dimension in the daily work".

\begin{tabular}{|c|c|c|c|}
\hline Meaning unit & $\begin{array}{l}\text { Connecting the meaning } \\
\text { unit in themes }\end{array}$ & Sub-themes & Main themes \\
\hline $\begin{array}{l}\text { "I'm not good at handling interpersonal relations". } \\
\text { "I have never learned to take responsibility or } \\
\text { initiative when dealing with other human beings". }\end{array}$ & $\begin{array}{l}\text { Shortcomings in relationships } \\
\text { with other persons } \\
\text { They lack knowledge about } \\
\text { relational contact }\end{array}$ & $\begin{array}{l}\text { Challenges to handle the } \\
\text { relational aspect in daily } \\
\text { work that is hard to } \\
\text { identify with }\end{array}$ & $\begin{array}{l}\text { The struggle to handle } \\
\text { the core dimension } \\
\text { of the daily work }\end{array}$ \\
\hline $\begin{array}{l}\text { "Ì try to avoid long conversation with the patients”. } \\
\text { "I only want to talk about somatic disease”. } \\
\text { "At times I don’t like the idea of going to work } \\
\text { when I know I need to work with colleagues } \\
\text { with whom I have little contact. I am only able } \\
\text { to identify with colleagues who view things } \\
\text { the way I do". }\end{array}$ & $\begin{array}{l}\text { Trying to avoid talking } \\
\text { about themes they don't } \\
\text { want to handle } \\
\text { They also try to avoid persons } \\
\text { they don't identify with }\end{array}$ & $\begin{array}{l}\text { Distance from relationally } \\
\text { demanding situations in } \\
\text { daily work }\end{array}$ & \\
\hline
\end{tabular}

Table 2. Summary of findings on critical factors for nurses in managing relationally demanding jobs.

\begin{tabular}{|c|c|c|}
\hline $\begin{array}{l}\text { The struggle to handle the core } \\
\text { dimension of the daily work }\end{array}$ & $\begin{array}{l}\text { Externally motivated choice of } \\
\text { education and work behaviour }\end{array}$ & Symptoms of burnout \\
\hline $\begin{array}{l}\text { Challenges to handle the relational aspect } \\
\text { in daily work that is hard to identify with }\end{array}$ & $\begin{array}{c}\text { Coincidence of } \\
\text { choice of education }\end{array}$ & $\begin{array}{l}\text { Feeling of being constantly } \\
\text { emotionally tired }\end{array}$ \\
\hline \multirow[t]{2}{*}{$\begin{array}{l}\text { Distance from relationally demanding } \\
\text { situations in daily work }\end{array}$} & $\begin{array}{l}\text { Work behaviour affected by a } \\
\text { need for positive feedback }\end{array}$ & Self-criticism \\
\hline & $\begin{array}{l}\text { Work behaviour affected by a strong } \\
\text { sense of responsibility }\end{array}$ & \\
\hline
\end{tabular}




\subsection{Ethical Considerations}

The study was approved by the Norwegian Social Science Data Service (NSD) and the Regional Committee for Medical and Health Research Ethics (REK) of Mid-Norway. Participants were informed that participation was voluntary and that confidentiality would be respected.

\section{Results}

\subsection{The Struggle to Handle the Core Dimension of the Daily Work}

\subsubsection{Challenges to Handling the Relational Aspect in Daily Work That Is Hard to Identify with}

The nurses stressed that the relational aspect of their contact with patients and relatives represented the essence of their professional activity and a key factor behind good work performance. However, they failed to identify with this part of their job and found it hard to communicate with patients and relatives, considering it unnatural to get too personally involved in patient relations. Several expressed that relational work was not suitable for them: "I find it hard to stay focused in my work as I'm not good at handling interpersonal relations".

The nurses further stated cultivation of interpersonal relations had never really appealed to them, neither in their childhood nor in their adulthood: "I have never learned to take responsibility or initiative when dealing with other human beings”. Another nurse claimed that she was not too preoccupied with personal relations and found it hard to maintain contact with people over time.

The nurses saw a great challenge in meeting people on their own terms. "One of the main challenges in this work is to try to meet people on the basis of their position, it is quite hard. It is hard to handle situations where you are not certain of what to do. It is difficult to be present all the time, as everything you say or do is being continuously observed". The informants experienced that the flexibility demanded of them at work kept draining their energy. "In this job they demand that you are flexible and I feel how I rapidly lose my energy. It is quite challenging to keep readjusting".

The nurses did not experience that the job is particularly meaningful in relation to other jobs, and one said that their work is not important enough to require the attention of others.

\subsubsection{Distance from Relationally Demanding Situations in Daily Work}

The nurses' feelings of inadequacy with regard to relational skills caused them to look for ways to reduce their involvement with patients and relatives. They tried to avoid long conversations with the illusion that they were busy with other tasks, and this way limited the conversations in some cases to apply only to information about the patient's somatic disease. "I tried to stay busy involving in other tasks, in order to avoid long conversations with the patients or their relatives". The nurses' experience of possessing inadequate relational skills also marked the relationship with their colleagues. In order to distance themselves from strain, they tried to avoid working with colleagues who didn't share their opinions. They were also unsure in relationships with colleagues they didn't know well enough. "At times I don't like the idea of going to work when I know I need to work with colleagues with whom I have little contact. I am only able to identify with colleagues who view things the way I do".

They were also frustrated in interactions with some colleagues who they perceived didn't share their opinions about how to be a good colleague and nurse. Five of the nurses considered themselves as good at helping colleagues, but did not always experience this as mutual, which caused irritation. "Sometimes I feel reluctance to go to work when I know that there are colleagues on duty who are not so willing to help when asking for help". While nurses had a sense of working alone a lot, they were very keen to watch how their colleagues performed their job, and they were concerned and highly annoyed by people who tried to evade the job. They were often surprised that their colleagues could handle chaos so well, and believed that it could indicate an easy attitude to the job. "Can say that what trigger a negative impact, are colleagues who try to make it easy for themselves at work." The nurses were also irritated that colleagues generally were not nice enough to give them positive feedback at work. They would often carry out their work on their own and focus on their own work performance. The relationship with their superiors was variable, and they did not consider it natural to see their superior when difficult situations occurred. They felt alone in carrying the burden of their reflections.

The feeling of limited support in their work environment meant that it was subsequently hard for them to experience a general sense of community at work, and some informants struggled to process events related to the 
patients.

\subsection{Externally Motivated Choice of Education and Work Behaviour}

\subsubsection{Coincidence of Choice of Education}

The nurses' choice of education was either regulated by a favourable labour market or by mere coincidence. Initially, they had all been planning different professional careers, but felt prevented by external circumstances to pursue their original plans. "I was a graduate in economics and was set to start working in the finance sector, but then the financial crisis struck and I instead opted for a nursing education". "I was not able to enter medical studies, so what could I do? I read through the study guide and thought: Nursing - three years of study and easy admission with my current grades". "Accidental choice of study, easy to find work". None of the nurses had earlier professional experience that was relevant for their choice of education.

\subsubsection{Work Behaviour Affected by a Need for Positive Feedback}

The nurses were eager to show that they were able to perform the job successfully. They were concerned about how their colleagues rated their work performance and the feeling of inadequacy in their daily work made it hard for them to put the work behind them after having ended their shift. "I feel bad when I have not been able to complete all my work tasks. Everything should be in order when I have completed my shift”. They often reflected on their job after leaving work and sometimes called colleagues at work in order to get a response to their reports and receive assurance that their work had been up to the mark. All informants held positive feedback to be a strong motivational factor in their work, though they were not satisfied with their colleagues' ability to provide such feedback. In order to cover their demand for response they had subsequently requested individual guidance.

\subsubsection{Work Behaviour Affected by a Strong Sense of Responsibility}

The nurses claimed to have a strong sense of responsibility and felt bad vis-à-vis their colleagues whenever they found their own work performance to be below par. The informants find it sometimes difficult to leave the work place after the end of the work day. "It is difficult to leave work tasks to my colleagues with a clean consciousness".

The informants also found it hard to stay away from work when they were ill. Even if they did not feel well they tended to show up at work, fearing that their absence would cause problems for their colleagues. To avoid sick leave, their spare time was mainly spent on recovering from their shift.

\subsection{Symptoms of Burnout}

\subsubsection{Feeling of Being Constantly Emotionally Tired}

The nurses had a feeling of being constantly emotionally tired, without being able to improve their situation. They were resigned and had a feeling of inadequacy with regard to both work and their private lives. They experienced the work as extremely demanding and often reflected on their job after leaving work. The nurses tended to experience resignation vis-à-vis parts of their job. "You can really be devastated by the fate of the patient, and then you become resigned and think that everyone has to die". Another nurse made the following statement: "At times I'm devastated by the fate of the patients and the certainty that they will pass away. It's almost unbearable". They felt alone in carrying the burden of their gloomy reflections. "I have nobody to discuss such matters with; I am too busy with my work". This often caused them to feel depressed and the accumulated strain soon developed into a festering wound. They often experienced stress and physical strain in the form of stiff shoulders, neck and back, and often experienced headaches. In their spare time they mostly watch TV or rest on the sofa. "My job is at times so intense that I really look forward to my days off, which I need for recovery in order to keep working. I often feel terribly stressed and tired after work, so I look forward to lying down on the sofa and sleep". "I don't have the surplus to do anything else than resting, and sometimes go for walks in the wilderness".

According to the nurses, they spent too much energy on the job, but felt unable to do anything about it. They were quite dissatisfied to realise that their job now demanded too much of their lives and negatively affected their private lives. Many years with a demanding job had drained their energy, and they found it exhausting to combine an exhausting job with their private lives. They struggled with a feeling of inadequacy and bad con- 
sciousness in relation to spouses and children. "My family has too often seen me exhausted and broken. This is the price I pay for my work. I sometimes reflect on whether it is good for me to work in such a place year after year, it drains energy from my private life”. The lack of surplus in some cases led to conflict with spouses and children, which represented a very exhausting experience for the informants.

The nurses wished to change their job, and find something simpler and less exhausting, but were sceptical about their prospects of getting other work and felt that alternative career paths had been closed off.

\subsubsection{Self-Criticism}

The nurses evaluated themselves in a critical perspective and both their professional conduct and family role became subject to critical examination. "I am critical of myself, which is the reason why I scrutinise my work the way I do". They were also dissatisfied that their work had not helped influence their choice of values in life. "I thought perhaps my work would improve my ability to do things that mean something to us, that are important to us. But in the end I often tend to focus on material issues”.

They also felt bad about not being able to maintain their own health and thought they should try to exercise in order to keep in shape. "I walk a lot at work, but my fitness should have been better. I should have done some weight training, though I don’t get beyond the planning stage”.

\subsection{Summary of the Results}

The summary of the findings indicates that the nurses did not identify with the core aspect of their work. They agreed that the relational aspect of their contact with patients and relatives represented the essence of their professional activity, but they failed to identify with this part of their job. They experienced inadequacy in their daily work performance, both in relation to patients and relatives, and to their colleagues. Their feeling of inadequacy in work caused them to look to distance themselves from relationally demanding situations. The nurses' work behaviour was externally motivated, and they held positive feedback from colleagues to be a strong motivational factor in their work.

The findings also indicate that the nurses experience symptoms of burnout in terms of emotional fatigue and critical self-evaluation, which may indicate that the demands exceeded the nurses' resources.

The nurses did not find their job particular meaningful and wanted an easier job, but had doubts about their ability to find other jobs that were suitable for them.

\section{Discussion}

This study on nurses working in hospital aimed at enhancing our understanding of critical factors for nurses in managing relationally-demanding situations in care for very ill and/or dying patients. Findings in the present study give new insight into potential barriers, described by the nurses as critical for managing relationallydemanding jobs, such as lack of; identification with the core aspect of the job, a match between personal capacity and demands, mutual support among colleagues, leadership support and internal motivation.

In line with the definition of burnout [9], the nurses showed symptoms of burnout, e.g. psychosomatic complaints such as stiff shoulders, neck and back pain, and headache, as well as dissatisfaction, anger and frustration and being emotionally tired. The results indicate that the nurses' experience of symptoms of burnout could be a result of demands that exceeded the nurses' resources.

Initially the nurses were eager to show that they were able to perform the job successfully, however, they experienced inadequacy in their daily practice as time progressed. They experienced that the external standards they tried to satisfy came into conflict with their personal preferences. In that way, it seemed that they failed to meet the requirements of their profession and handling different aspects, like patient relationships and the flexibility of the profession. This situation significantly affected the relationship with their families, since they prioritised work and remained eager to show their professional skills. The failure to meet these introjected standards may have contributed to negative feelings and self-criticism in addition to symptoms of burnout in terms of emotional fatigue and problems in maintaining their health over time [1] [5]-[8].

The consequence of not identifying with an activity, not feeling competent to perform it or not believing that their contribution made a difference could possibly have caused further depletion of mental resources [7]. The nurses' choice of education was relatively haphazard and often motivated by securing a stable job. In contrast to experiencing job engagement-marked by vigour, dedication and absorption-the nurses expressed that they 
could not identify with the core aspect of the job, relational contact with patients and relatives, implying that they were likely to find their jobs less interesting, enjoyable or satisfying [26].

Interpersonal relationships, professional conflict and the emotional cost of caring therefore represented potential sources of stress and burnout among the nurses [1]. The fact that they could not identify with the job might therefore be seen in conjunction with effort expenditure which in turn is related to physiological and psychological costs [11]. Thus, one might argue that the work behaviour of the nurses was motivated by material and social conditions. Externally motivated work behaviour might therefore be one explanation of why the nurses experienced symptoms of burnout in terms of emotional fatigue and problems in maintaining their health. These findings are in line with previous findings [9], suggesting that less commitment and poorer performance than other workers could potentially cause a number of health complaints [10].

One explanation of why employees adopt external standards without fully identifying with them is a strong and internalised ethic of responsibility [13]. Hence, a strong internalised work ethic among professional groups could cause the development of burnout [27]. Initially the nurses seem to put the needs of others first and to do whatever it took to help the patients, in spite of the consequences for their own health. These findings subsequently add support to earlier findings suggesting that an internalised ethic of responsibility [13] as well as the emotional labour that marks the everyday practice of human service professionals, including nurses, could represent factors that predict burnout [14]. Moreover, the nurses mentioned insufficient social support and possibilities for recovery during the day, forcing them to begin a new day at work not fully recovered from the previous one. The result of this was an increased intensity of negative load reactions. Insufficient recovery, mental or physical, may lead to an accumulation of negative load effects such as exhaustion and psychosomatic complaints, eventually becoming irreversible [28]. Could the signs or symptoms of burnout been discovered earlier in order to prevent an irreversible exhaustion? What are the critical factors to address in order to strengthen the ability to manage relationally demanding jobs? Based on the findings in present study, and previous studies indicating that the interaction between individuals and their environment represents the basis for motivation, behaviour and the possibility for personal growth [19], one might argue for the particular importance of finding a true match between personal capacity and job demands in relationally demanding jobs. Although the findings in the present study indicate that the personal resources available have a significant impact on the process from high goals and enthusiasm to experiencing burnout in hospital nurses, we should not underestimate the relevance of contextual factors. Identification of contextual factors that improve job-motivation [19] might be of great importance to enable employees to escape the negative cycle of burnout. Findings in the present study indicate the relevance of leadership training for nurse managers. A workplace where employees receive encouragement and support in the development of their interpersonal, emotional and job skills might provide a range of internal and external opportunities for employees to build their repertoire of competencies required. Thus, in order to enable employees to leave the negative cycle of burnout it seems critical to develop a well-functioning social support system that captures symptoms of burnout at an early stage.

\section{Study Limitations}

The current study has some limitations. A small number of participants representing one profession limit the generalisation of the study's discoveries. The selection of participants may also have influenced the type of information that emerged. Whether the people selected were the most suitable ones to participate in the interviews is open to debate, though there is no doubt that the relevant profession is among the most demanding types of relational work. A different composition of informants or professions might have yielded different results. Furthermore, the contents of the interview guide could perhaps affect the information collected. Based on the research method it is not possible to identify the point when the symptoms of burnout emerged, and it is not possible to make any assumption about causal relationships. However, the study identifies several motivational factors that could potentially be linked to erosion of enthusiasm over time.

\section{Conclusion and Practical Implications}

The study showed that lack of identification with the core aspect of the job, relation contact with patients and relatives, and external motivation were potential barriers for nurses in managing relationally demanding jobs. The work behaviour of the nurses was motivated by material and social conditions, and they could not identify with the core aspect of the job. The nurses were in the process of losing their enthusiasm and showed symptoms 
of burnout. Externally motivated work behaviour might be one explanation for why nurses experience symptoms of burnout. The results therefore underscore the importance of an early response to employees who are beginning to struggle at work. Working in a job where serious emotional strain is a daily challenge requires a certain amount of personal resources, underlining the relevance of a true match between personal capacity and job demands. Moreover, support among colleagues and leadership are considered critical to prevent a negative process of burnout and helping to manage relationally demanding jobs. The nurses in this study had a feeling of working alone frequently and were unable to find support from others apart from colleagues who shared their opinions. This kind of withdrawal from colleagues should be addressed by the social support system at work at an early stage. In order to manage relationally demanding jobs and prevent burnout, individual guidance and advice as well as opportunities within the organisation should be discussed in order to identify challenges in line with these personal resources.

\section{Competing Interests}

The authors declare that they have no competing interests.

\section{Authors' Contributions}

ABB carried out the design of the study, collected data, performed the analysis and drafted the methods and results. ABB and ML discussed the result of the data analysis. ML drafted the introduction, ABB and ML drafted the discussion section, and $\mathrm{ABB}$ and ML prepared the manuscript. All the authors read and approved the final manuscript.

\section{Acknowledgements}

The authors would like to thank the nurses for their generous participation in this study.

\section{References}

[1] McVicar, A. (2003) Workplace Stress in Nursing: A Literature Review. Journal of Advanced Nursing, 44, $633-642$. http://dx.doi.org/10.1046/j.0309-2402.2003.02853.x

[2] van der Doef, M., Mbazzi, F.B. and Verhoeven, C. (2012) Job Conditions, Job Satisfaction, Somatic Complaints and Burnout among East African nurses. Journal of Clinical Nursing, 21, 1763-1775. http://dx.doi.org/10.1111/j.1365-2702.2011.03995.x

[3] Maslach, C., Schaufeli, W.B. and Leiter, M.P. (2001) Job Burnout. Annual Review of Psychology, 52, 397-422. http://dx.doi.org/10.1146/annurev.psych.52.1.397

[4] Bakker, A.B. and Demerouti, E. (2008) Towards a Model of Work Engagement. The Career Development International, 13, 209-223. http://dx.doi.org/10.1108/13620430810870476

[5] Deci, E.L. and Ryan, R.M. (2002) Handbook of Self-Determination Research. University of Rochester Press, Rochester, $\mathrm{X}, 470 \mathrm{~s}$.

[6] Ryan, R.M. and Deci, E.L. (2000) Self-Determination Theory and the Facilitation of Intrinsic Motivation, Social Development, and Well-Being. American Psychologist, 55, 68-78. http://dx.doi.org/10.1037/0003-066X.55.1.68

[7] Ryan, R.M. and Deci, E.L. (2000) Intrinsic and Extrinsic Motivations: Classic Definitions and New Directions. Contemporary Educational Psychology, 25, 54-67. http://dx.doi.org/10.1006/ceps.1999.1020

[8] Vallerand, R.J., Pelletier, L.G. and Koestner, R. (2008) Reflections on Self-Determination Theory. Canadian Psychology/Psychologie Canadienne, 49, 257-262. http://dx.doi.org/10.1037/a0012804

[9] Maslach, C., Jackson, S.E. and Leiter, M.P. (1997) Maslach Burnout Inventory. In: Evaluating Stress: A Book of Resources, 3rd Edition, Scarecrow Education, Lanham, 191-218.

[10] Shirom, A. and Melamed, S. (2005) Does Burnout Affect Physical Health? A Review of the Evidence. In: Research Companion to Organizational Health Psychology, Edward Elgar Publishing, Northampton, MA, 599-622.

[11] Meijman, T.F. and Mulder, G. (1998) Psychological Aspects of Workload. In: Drenth, P.J.D., Thierry, H. and de Wolff, C.J., Eds., Handbook of Work and Organizational Psychology, Psychology Press/Erlbaum, Hove, 5-33.

[12] Taris, T.W., Schaufeli, W.B. and Shimazu, A. (2010) The Push and Pull of Work: The Differences between Workaholism and Work Engagement. In: Bakker, A.B. and Leiter, M.P., Eds., Work Engagement: A Handbook of Essential Theory and Research, Psychology Press, New York, 39-53. 
[13] Wu, S., Zhu, W., Li, H.Y., Wang, Z.M. and Wang, M.Z. (2008) Relationship between Job Burnout and Occupational Stress among Doctors in China. Stress and Health: Journal of the International Society for the Investigation of Stress, 24, 143-149. http://dx.doi.org/10.1002/smi.1169

[14] Zapf, D., Seifert, C., Schmutte, B., Mertini, H. and Holz, M. (2001) Emotion Work and Job Stressors and Their Effects on Burnout. Psychology \& Health, 16, 527- 545. http://dx.doi.org/10.1080/08870440108405525

[15] van Beek, I., Hu, Q., Schaufeli, W.B., Taris, T.W. and Schreurs, B.H.J. (2012) For Fun, Love, or Money: What Drives Workaholic, Engaged, and Burned-Out Employees at Work? Applied Psychology: An International Review, 61, 30-55. http://dx.doi.org/10.1111/j.1464-0597.2011.00454.X

[16] Peters, L., Cant, R., Sellick, K., O’Connor, M., Lee, S., Burney, S. and Karimi, L. (2012) Is Work Stress in Palliative Care Nurses a Cause for Concern? A Literature Review. International Journal of Palliative Nursing, 18, 561-567. http://dx.doi.org/10.12968/ijpn.2012.18.11.561

[17] Spooner-Lane, R.S.P. and Wendy, A. (2007) Determinants of Burnout among Public Hospital Nurses. Australian Journal of Advanced Nursing, 25, 8-16.

[18] Laschinger, H.K. and Smith, L.M. (2013) The Influence of Authentic Leadership and Empowerment on New-Graduate Nurses’ Perceptions of Inter-Professional Collaboration. Journal of Nursing Administration, 43, 24-29. http://dx.doi.org/10.1097/NNA.0b013e3182786064

[19] ten Brummelhuis, L.L., ter Hoeven, C.L., Bakker, A.B. and Peper, B. (2011) Breaking through the Loss Cycle of Burnout: The Role of Motivation. Journal of Occupational and Organizational Psychology, 84, 268-287. http://dx.doi.org/10.1111/j.2044-8325.2011.02019.x

[20] Smith, J.A. and Osborn, M. (2008) Interpretative Phenomenological Analysis. In: Smith, J.A., Eds., Qualitative Psychology: A Practical Guide to Research Methods, Sage, London, 53-80.

[21] Denzin, N.K. and Lincoln, Y.S. (2000) Handbook of Qualitative Research. Sage, Thousand Oaks.

[22] Smith, J.A. and Osborn, M. (2004) Interpretative Phenomenological Analysis. In: Breakwell, G.M., Ed., Doing Social Psychology Research, Blackwell Publishing, England, 229-254.

[23] Smith, J.A. and Dunworth, F. (2003) Qualitative Methodology. In: Valsiner, J., Ed., Handbook of Development Psychology, Sage, London, 603-621.

[24] Kvale, S. (1996) Interviews: An Introduction to Qualitative Research Interviewing. Sage, Thousand Oaks.

[25] Patton, M.Q. (2002) Qualitative Research \& Evaluation Methods. 3rd Edition, Sage, Thousand Oaks, 427 s.

[26] Salanova, M. and Schaufeli, W. (2008) A Cross-National Study of Work Engagement as a Mediator between Job Resources and Proactive Behaviour. The International Journal of Human Resource Management, 19, 116-131. http://dx.doi.org/10.1080/09585190701763982

[27] Schaufeli, W. (2007) Burnout in Health Care. In: Carayon, P., Ed., Handbook of Human Factors and Ergonomics in Health Care and Patient Safety, Lawrence Erlbaum, Mahwah, 217-232.

[28] Schaufeli, W.B., Taris, T.W. and van Rhenen, W. (2008) Workaholism, Burnout, and Work Engagement: Three of a Kind or Three Different Kinds of Employee Well-Being? Applied Psychology: An International Review, 57, $173-203$. http://dx.doi.org/10.1111/j.1464-0597.2007.00285.x 
Scientific Research Publishing (SCIRP) is one of the largest Open Access journal publishers. It is currently publishing more than 200 open access, online, peer-reviewed journals covering a wide range of academic disciplines. SCIRP serves the worldwide academic communities and contributes to the progress and application of science with its publication.

Other selected journals from SCIRP are listed as below. Submit your manuscript to us via either submit@scirp.org or Online Submission Portal.
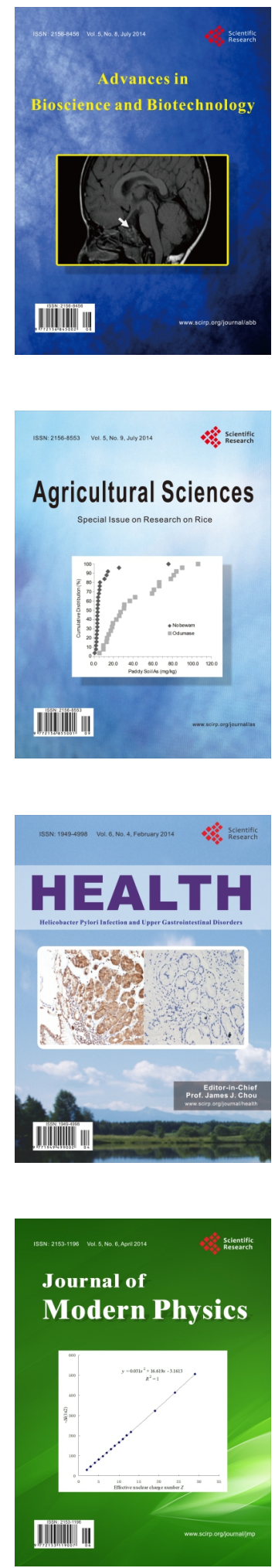
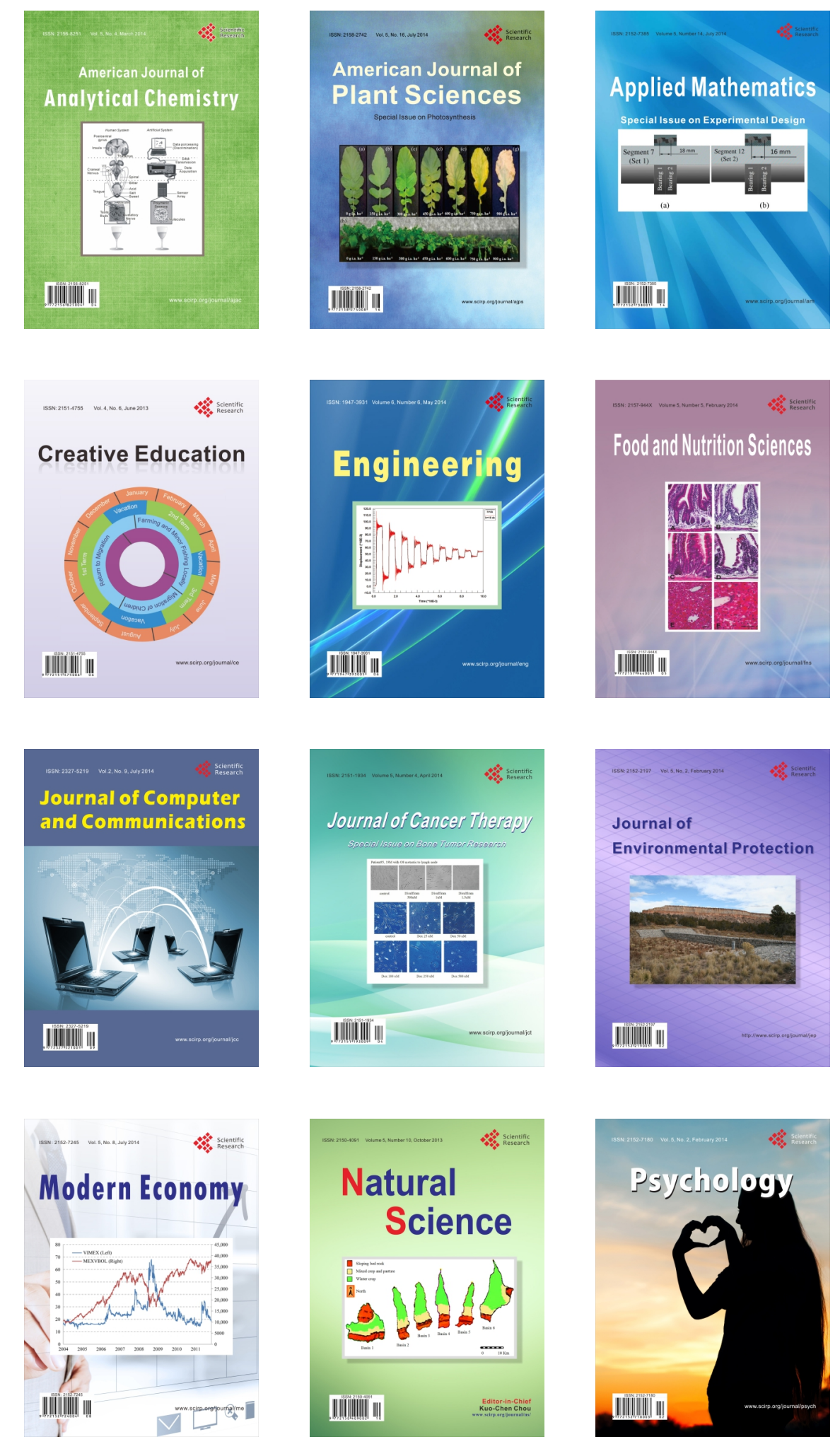